\title{
Tetania da lactação da égua: relato de caso
}

Fernanda Tamara Neme Mobaid Agudo Romão; Camila Agostinho Sartori, Renan Borges Inacio, Sofia de Barros Botacini, Silvana Rui Martins da Cruz, Cristhian de Almeida Barbosa, Andrea Rebeca Ferreira Vasconcelos, Gabriel Franco Simões, Ana Carolina Aiello Dall Ben, Willian Rodrigues Inacio, Bianca Gerardi

Faculdade de Ensino Superior e Formação Integral (FAEF), Garça, SP, Brasil

*Autor correspondente

e-mail: ftnmaromao@gmail.com

\section{Resumo}

A hipocalcemia é uma condição relativamente rara em equinos, podendo ser denominada tetania da lactação, do transporte ou hipocalcemia idiopática. Os sinais clínicos são tônus muscular aumentado, marcha rígida, ataxia, fasciculação muscular, principalmente dos músculos temporal, masseter e tríceps, trismo, disfagia, salivação, transpiração profusa, taquicardia, arritmias, convulsão, coma e morte. Essas alterações podem ser progressivas em éguas lactantes e em 24 a 48 horas os animais podem morrer. Em casos leves, o tratamento não se faz necessário, entretanto, nos casos graves recomenda-se a administração de soluções de borogluconato de cálcio a 20\%, na dose de 250 a 500 mL/500 kg, diluídas em solução salina ou glicose. A maioria dos casos responde rapidamente à terapia, e em uma minoria pode ocorrer recidiva. O presente trabalho tem por objetivo relatar um caso de tetania da lactação em uma égua, juntamente com a terapêutica de sucesso. Foi atendido no Hospital Veterinário de Grandes Animais da Faculdade de Ensino Superior e Formação Integral- FAEF, um equino fêmea, da raça Quarto de Milha, com 9 anos de idade, pelagem rosilha, pesando $510 \mathrm{~kg}$, no $10^{\circ}$ dia de lactação. Segundo o veterinário que encaminhou a égua, na noite anterior, após ter sido coberta por monta natural, sem nenhuma intercorrência, começou a apresentar sinais neurológicos como andar espástico, lábios duros, e ataxia. Na chegada ao hospital veterinário foi realizado exame físico geral que demonstrou as seguintes alterações nos parâmetros vitais: frequência cardíaca 80 bpm, frequência respiratória 44 mpm e ausência de motilidade intestinal em todos os quadrantes abdominais. 0 exame neurológico demonstrou incoordenação motora grau 3/5, andar espástico, rigidez muscular, fasciculação em masseter, tríceps e costado, pescoço rígido com escoliose para o lado direito, lábios rígidos e voltados para o lado direito, trismo mandibular com incapacidade de apreensão e mastigação do alimento, ausência de sensibilidade da hemiface direita e esquerda, ausência de tônus de cauda e lateralizarão para o lado direito, diminuição do reflexo do esfíncter anal e incontinência urinária. 
Com base nos sinais clínicos, a suspeita de tetania da lactação foi estabelecida, juntamente com a suspeita de trauma craniano ou medular. Foi realizada a reposição hidroeletrolítica, intravenosa, com 30 litros de solução de ringer lactato com $10 \mathrm{~mL}$ de borugluconato de cálcio diluído até totalizar $300 \mathrm{ml}$ de reposição. A égua também foi medicada com flunixim meglumine e ocitocina para facilitar a ejeção de leite para o potro. A partir do $4^{\circ}$ litro de ringer com lactato já houveram sinais gradativos de melhora, como diminuição das fasciculações, relaxamento da musculatura, diminuição do trismo mandibular, diminuição da arritmia e retorno dos movimentos intestinais; de maneira que no $15^{\circ}$ litro de ringer lactato com cálcio, o animal estava sem alterações neurológicas evidentes e passou a se alimentar normalmente. Neste caso, o diagnóstico de tetania da lactação foi terapêutico, devido à resposta imediata à reposição do cálcio intravenosa, sendo que os sinais clínicos foram desaparecendo gradativamente ao longo da administração. Por se tratar de uma doença metabólica rara, a tetania da lactação deve ser sempre considerada em casos neurológicos com evolução extremamente aguda, como no caso descrito, e em éguas lactantes. 0 tratamento é relativamente simples e a resposta à terapia é imediata.

Palavras-chave: Hipocalcemia. Égua lactante. Sinais neurológicos. 